\title{
The Mediator's Role in Philippine Schools Overseas (PSO's)
}

\author{
Alexander S. Acosta
}

\begin{abstract}
Within the eclectic history of conflict research, subsuming number of theories and models of conflict resolution, the roles of mediators are often labeled based on cultural milieu. Using an in-depth semi-structured interview, this phenomenological study probed into the conflict mediation of 10 school administrators representing the Philippine Schools Overseas in the United Arab Emirates, the Sultanate of Oman and the State of Qatar with a view to understanding their unique roles as mediation persona. Transcribed field texts were read and reread for purposes of naïve understanding after which a structural analysis was done via a dendogram. To emerge a collective and comprehensive understanding of the phenomenon, transcendental subjectivity was observed and was first subjected to the member- checking procedure. Themes were emerged following the inductive approach in theme development.

Interestingly, results of cool and warm analyses paved the identification of trilogy of mediator's roles at Philippine Schools Overseas School administrators namely bracketing, balancing, and blending roles. The emerged mediator's trilogy of roles expands the overall capability of school leaders while viewing their role not only from the technical and managerial perspective but also from the humanistic point of view where conflict resolution is treated and interpreted in a way that it is less stressful yet humane and productive.
\end{abstract}

Index Terms-Balancing role, blending role, bracketing role, Philippine school overseas.

\section{INTRODUCTION}

Mediation is usually considered as one of the primary tools of conflict resolution in both civil and international conflicts Wall, Stark, and Standifer, [1], Wagner, P., Weiss, C., Wittrock, and Wollman, [2], Kleiboer, and Hart, [3], Vasquez, Turner, Sanford, and Stamato, L. [4], Whiten and Ham, [5], Mitchell, \& Webb. [6], Kressel, and Pruitt, [7]. It is one aspect of outside intervention in which a third party attempts to assist the parties in settling the dispute through mutual agreement Rubin, Pruitt, and Kim [8]. Mediators are usually thought to be more effective, unbiased, or have no preferences for issues in dispute. Within the eclectic history of conflict research, subsuming theories and models of conflict resolution, roles of mediators are often labeled based on cultural milieu. Arab mediators see their task as restorers of harmonious relationships between disputants and preserving Arab unity, as opposed to finding common ground on which the dispute might be resolved Cohen, [9], Patai, [10]. Indian mediators aimed at preserving community

Manuscript received July 3, 2014; revised September 10, 2014

The author is with the Philippine School Doha, Qatar and Technological University of the Philippines, Graduate School, Manila, Philippines (e-mail: xandreacts@yahoo.com). harmony Singh and Singh [11]. In China,

Callister, and Wall [12], Wall and Blum [13] have identified carefully non-assertive style of mediation. Jocano, [14] emphasized that conflict in the Philippines is culturally rooted that emanates from political fragmentation during the emergent phase of cultural to Baranganic phase from 14th century A.D. to 16th century A. D. where Datu was the third party. In religious institutions, the ministers, priests, and rabbis who may be called on to assist in member disputes, do not view this mediation as one of their primary responsibilities because they are egalitarian Callister and Wall, [15]. In intra-state conflict Regan, [16] found that the mediator's role contributes to the cessation of hostilities in certain conditions. In a wider perspective, the mediator's role is used in multiple contexts. In civil cases as an alternative to litigation and small claim disputes Vidmar, [17]and marital disputes ref [7] industrial relation conflicts Brett and Goldberg, [18] political disputes led by [14] and environmental disputes Folberg and Taylor [19] among others. All these and more describe the complexity of the mediator's role in a wider scale; thus, his persona in conflict mediation is a vital management phenomenon which should not be underestimated nor taken for granted.

In instances relying on human-need thinking, unsuccessful socialization may result from the mediation of acutely discrepant worlds Berger and Luckman [20] where the mediator's facilitative role is emphasized Burton, [21]. The facilitator is considered expert who assists parties in recognizing his or her true - and ultimately shared - human needs, and therewith, to help them overcome differences Bercovitch, [22], Princen, [23]. Corollary to this impression, the Philippine Schools Overseas, as a dynamic human organization, saw the ripe moment of disagreements and misunderstanding between and among employees prompting from a very simple to a more complicated and serious conflicts. Thus, the call for a third party intervention is always at hand. Among those social activities and organizations where the roles of mediators have been theorized and empirically studied, [6], [21], Popkewitz, [24] little is known about the role of school administrators in conflict mediation in the context of learning institutions where conflict tendency can neither be avoided nor can be neglected. It is assumed that the facilitator knows more about the causes and processes of human behavior than the participants themselves, and that he will act as an outside observer in the assisted negotiation process Touval and Zartman, [25]. Imperatively, since conflict is culturally rooted [14] this phenomenological inquiry argues that the role of school administrators in the Philippine Schools Overseas as conflict mediators isembedded in their daily 
operation of the school where eclectical conflicts among employees and school stakeholders need careful deliberation, immediate intervention and productive mediation process. Interestingly, the fascinating stories of a select group of school administrators in Philippine School Overseas paved the way to address the central question of this phenomenological inquiry: "What does it take to be a conflict mediator?"

Findings of the study offer a new thread of the mediation role of administrators across disciplines. As leaders, it is their primordial role to behave in a moral way and to make decisions not on matter of slavishly following rules, but frequently they are required to make decisions that have moral implications in maintaining healthy relationship between and among members despite individual and cultural differences. This also generates source of practical reference in conflict mediation within the present time.

\section{METHOD}

\section{A. Study Design, Locus, Sample and Instrumentation}

To surface the roles that school leaders play in conflict mediation, a phenomenological design McWilliam, Kothari, Ward-Griffin, Forbes, Leipert [26] was used. Ten school administrators representing the Philippine Schools Overseas particularly in Middle East countries such as the United Arab Emirates, Sultanate of Oman and State of Qatar were purposely selected. Selection of study participants were based on the following inclusion criteria, (a) at least two years length of service in school and (b) are masters degree holder. To gather needed data and information, a two-part instrument was used in this study. The first part was a robotfoto Keltchtermans and Ballet, [27] a Dutch term which means a cartographic sketch of the subject, detailing the gender, age, work affiliation, length of stay in the country and a short description of their role as school administrators. The second part was a semi-structured interview considered to be windows into the minds of informants' lived world Atkinson and Coffey, [28], Dingwall, [29], Silverman, [30].

\section{B. Data Collection and Ethical Consideration}

The main source of corpus data in this study was through interviews which served as the avenue of expressions, Bogdan and Biklen, [31]. in which questions were directed to the subjects' experiences, feelings, beliefs and convictions, Welman and Kruger, [32]. Prior to the interview of respondents, written communications were sent to the school principals of target schools and the school board of trustees requesting for their consent of such purpose then followed by a friendly visit to schools where appointment of time and place was set for the said interview. A two-hour interview was personally conducted in English in the most easing manner giving the assurance to respondents that responses on the questions will be treated with utmost confidentiality. Audio and video recording of the interviews was sought for transcribing purposes. Although the interview was done in English, it was inevitable that sometimes responses were delivered in Filipino. Hence, extended texts were carefully translated from emic to etic perspective.

\section{Mode of Analysis}

To surface the essence of the phenomenon under study, a 3-part structural analysis was observed. First, transcribed data were read and reread for purposes of naïve understanding. Then, the translated meaning units were structurally analyzed (see Fig. 1) via a dendogram Faulkner and Sparkes, [33] in which data were grouped into similar themes as expressed by the participants. Finally, a comprehensive understanding was surfaced guided by the researchers' vigilance and bracketing. Themes emerged and were subjected to member checking procedures to ensure validity and data trustworthiness, [28].

\section{FINDINGS}

This study yielded three interesting themes as revealed in the verbalizations and articulations of a select group of school administrators and school board of trustees in the Philippine School Overseas (PSOs), Middle East. Such responses have led to respond to the central question: "What does it take to be a mediator?" Evidently, Fig. 1 shows the mediator's trilogy of Roles, namely: bracketing role, balancing role and blending role. In the Bracketing role, the mediator must bear in mind that he possesses three mediating attributes before going into mediation, namely: non partisan, impartial and regulative. In the blending role, the mediator must project his redemptive, emulative and consultative attitude for the good of his people. The balancing role is purposely in between the two roles with the belief that a mediator should always examine himself if he exudes the attributes of being credible, astute, and trustworthy before engaging himself in mediation.

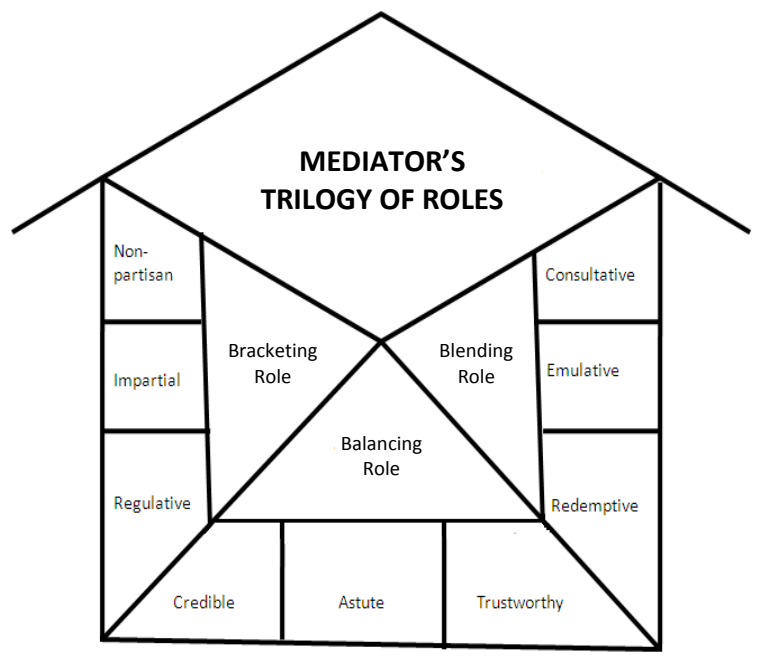

Fig. 1. Mediator's trilogy of roles.

\section{A. Bracketing Role}

Mediating conflict is not an easy task. It requires boldness and courage for individuals to play their role as conflict mediator. When with the disputants, the mediator must ensure that he has the mediating attributes of being non-partisan, impartial, and regulative. Such attributes are prelude before he attempts to resolve disputes. Statements of school administrators, based on the findings of this study, support this claim as they muse that when they conduct the 
mediation process they have to play their role as authorities over disputants regardless of relational knit with them.

"Work should not be stained with a person who is close to me. If closeness affects my role as a mediator then I am good for nothing. Even how close or how intimate my relationship with the involved party, I still have to pursue my role with no mental reservation."

"When it comes to an issue that affects the school, whether he or she is a family member, or a very close friend, there should be a limit to it, because that is where fair judgment comes in."

The sharings described that school administrators never consider personal attachment or relationship with their employees but they ensure of their non-political or nonpartisan figure in conflict mediation. While conducting mediation proceedings, one school administrator described that the proceedings were aligned with regulated terms and conditions reflected in the manual of norms and policies of the school. He said, "I am a member of the policy-making body of the school ensuring that the school runs smoothly leading to the right direction based on the established policy" to ensure smooth flow of the investigation. "We have the Manual of Norms and Policies of the school to be followed." This indicates the systematic measure of mediation grounded on established rules.

On matters pertaining to impartiality, school leaders were also aware of their role that decisions or resolving issues should be based on the merit of evidence and the weight of surfaced truth. Two school administrators had their sharing when asked what they would consider in making decisions. They said, "The benefit of both parties they can get after the investigation and based on the gathered verified data." "The effect of the conflict, the veracity of the issue and the surfaced truth would be my bases in coming up with a decision."

It is interesting to note that "Bracketing Role" as conflict mediator needs objectivity of the mind that ensures success in conflict mediation. These mediation attributes ascertain peaceful resolution of conflict when they freely flow within the reflective thought of the mediator.

\section{B. Balancing Role}

Communing with oneself means knowing the inner self of the individual. When asked about their unique characteristics that sustained their leadership influence, school administrators averred:

"Passion, commitment, heart and mind grounded by the LORD'S enlightenment that balances uncertainties, challenges, and problems are my characteristics that made me stay in the service. Realizing that true service is not for fame but most of the time puts one into shame and humiliation."

"It takes courage and unquestionable dedication to lead the school and it takes to be very reflective and wise with astuteness at all times particularly in resolving conflicts that seemed so difficult to solve."

These verbalizations personify the inner being of an individual that typifies a reflective astuteness before attempting to mediate conflict. Relative to this, two administrators conveyed:

"When I choose a person to be terminated, I did not just come up with a decision overnight; it has to be several nights. I have to see some factors to consider."

"There are two aspects in making decisions. One aspect is through actual logic, the scientific way of making decisions. The second thing is, I made sure it is acceptable to both parties in a win-win situation, ensuring that my decision will not create another problem in the future."

Furthermore, being with self also requires assessment whether one possesses credibility and trustworthiness which are also essential elements in maintaining leaders' capability of to mediate conflict. This was proven by the response of one administrator when asked to describe his role as school principal.

"My role as a school principal is somewhat like that of a model. I have to serve as a model, an example to my people. Because everyone looks up to me on how I behave as a person so I must carry with me the trust and credibility that my people gave me. In this way I can easily mediate them should conflict between and among members arise."

Unless a person knows himself or herself fully the purpose of his existence in the organization, he cannot enter into the consciousness of his peers, colleagues or subordinates. Portraying his role as conflict mediator requires astuteness, credibility, and trustworthiness of a leader which can only be acquired through respect earned from the group that emanates from the inner self of an individual.

\section{Blending Role}

The roles of PSOs school administrators are broad and tractive eyed not only with colleagues but also with other school stakeholders such as parents and community organizations. As conflict mediators, they also have the role to go back to the members of the group and relay their insightful moves during the mediation process. Thus, it is interesting to have a glimpse of the articulations of school administrators on how they behave whenever with the group. One school administrator strongly said, "I always practice consultative mediation on matters pertaining to school's day to day operation so that my members will always be aware that they are part of the system which means that success and failure of the school do not depend solely on me but on a collective endeavor."

This consultative mode is an attributing factor of leadership that made him realize the values of the role of his members in the system. Two respondents reacted positively and gave their share that having this consultative mode of mediation would also be strengthened if leaders shall also possess a leadership influence rooted in being redemptive and emulative in leading their people. When leaders asked how they exercised their influence, they articulated:

"Influence to me is modeling, when other people mirror me as an individual, as a leader or a person. If they follow what I say and they respect my word, it means that I have a 
great influence to them. There is something in me that they appreciate and emulate as their leader."

"Influence is a word that magnetizes people to follow
oneself without enforcing coercion."

When asked how they normally solve conflict at the workplace. Administrators vehemently remarked:

"I solve it amicably in a friendly way that is based on investigation."

"If it can be solved in a friendly way, then I have to do it as diplomatic as possible just to restore and maintain the relationship between and among members of my team."

Undoubtedly, the verbalizations of PSO's school administrators gave a true picture of how they should manage the disputes such that the employer-employee relationship should be maintained or can be restored. In other words, school administrators are always held responsible for whatever the school may have become under their leadership. Hence, these three leadership prongs, namely consultative, emulative and redemptive are essential facets of leadership influence known as the blending role of mediators when being with the group.

\section{DISCUSSION}

While the success of mediation depends on the mediator's influence on the group, findings in this phenomenological study revealed that school administrators play a vital role as mediators by meeting together with disputants (Bracketing Role), gathering information from them (Balancing Role), and listening to each side or by meeting with one disputant then taking information and ideas to the other side (Blending Roles). These roles are seminal attempts on mediation which run parallel to ref [15] which consists of three avenues of power, namely : the goal, expectancy, and reinforcement known as mediator's guide on mediation. Interestingly, these guides actualize the role of school administrators as conflict mediator's trilogy of roles, namely: bracketing role, balancing role and blending role. Each role is cloaked with leadership attributes that can help attain the purpose of mediation.

\section{A. Bracketing Role}

The role of school administrators in PSO's as conflict mediator cannot be underestimated. It always carries with a challenging task to exercise neutrality and projects objectivity in making decisions. Such objectivity plays within the plethora of leadership mediating attributes to be non-partisan, impartial and regulative when being with the disputants. By definition, third parties do not usually have a strong partisan position on the substantive issues in dispute; rather, they attempt as their raison d'etre to help parties reach a settlement, to be more or less neutral, and favor the substance (outcome) and/or procedure (process) in their intervention Lewicki and Sheppard, [34]. Non-partisanship resembles neutrality in resolving disputes without extending doubt to both erring parties. [16] For a mediator to be non partisan, he must possess two important characteristics: namely, unbiased, not preferring outcomes that favor one side to the other, and, equally important, can have an aversion to enduring disagreements. In similar vein, non-partisanship embraces impartiality of decision which Young, [35] reiterated that "the existence of a meaningful role for a third party depends on the party's being perceived as an impartial participant in the sense of having nothing to gain from aiding. Impartiality is neither an indispensable condition of acceptability, nor a necessary condition for successful performance of an intermediary's functions Touval, [36]. Contrary to what other scholars claim, they questioned the value of mediator impartiality Touval, [37], [25]. However, [25], for their part, argue that mediators are seldom indifferent to the terms being negotiated with. Even when seeking peace in the abstract, they try to avoid terms not in accord with their own interests. They see mediation as an exercise in power politics: "leverage is the ticket to mediation" [25]. Mediators apply leverage to one side and or the other to extract concessions.

On the same impression, school administrators must take note of the willingness to act in a sense of fairness that requires disputants to be willing to sacrifice in fostering healthy relationship at the workplace and pay respect to policies therein established when mediation takes its course. In other situations, the mediator must alter the parameters of the situation, through the use of various strategies such as provision of information, positive inducements, or even sanctions imposed on the disputants Terris and Maos, [38]. From the mediator's perspective, the more 'transformable' the conflict, the more 'solvable' it is thus fostering contract between conflicting parties may regulate change of perceptions by exposing each to information discrepant with their previously held images Stein, [39]. Moreover, the role of PSOs school administrators as conflict mediators is regulative in nature in order to attain peace in the mediation process. Thus, peace encompasses a wide range of policy options to end conflicts in a more objective and beneficial to both disputants Bassiouni, [40]. Neutral mediators are often thought to act in a regulative manner by providing certain policies and conditions during the mediation process. Through these terms and conditions, conflict mediation can be facilitated with urgency and the attainment of conflict resolution will be realized. Corollary to this, Felstiner, and Williams, [41] develop ways on how mediation should be undertaken: $a$. words of welcome and introduction $b$. description of the mediation project and its rationale. $c$. explanation of mediator's role $d$. the rule of strict confidentiality- mediator is sworn to silence about the proceedings. $e$. the fact that mediator will take note for use during the hearing only and will destroy them afterwards. $f$. how the session will be conducted: panelists will listen to everyone, then work with the disputants to explore possible ways to resolve the problem. $g$. it will be the disputants themselves, not the mediators, who will fashion any agreement that may be made. The probability of resolving conflict, under this standard is observed that mediator's role is to facilitate the flow of mediation. Intuition might suggest that only an unbiased mediator can establish regulation on conflict mediation who can credibly provide such information because only an impartial source could be trusted Darwall, [42]. 
Bracketing role epitomizes the role of mediators who is simply interested in minimizing the probability of conflict endurance. If the mediator is believed to be non-partisan, impartial and regulative, respect is gained and the likelihood of a peaceful settlement may be achieved.

\section{B. Balancing Role}

Exuding characteristics of a leader in conflict mediation, findings in this study indicate that to commune with self runs balance with relationship of the inner being where leadership attributes thrive. Gadamer [43] for his part, opined that to be in equilibrium means 'being with self 'and is itself a self-interpreting activity. This activity involves an understanding of what 'being' means, and it is this understanding that opens up a clearing in which human beings can encounter objects, institutions, and other human beings. Responses to conflict are thus learned and can be relearned by direct analysis of past behavior and by education and behavior-shaping programs Hocker and Wilmot, [44]. It is conclusive that leadership attributes are both acquired and innate. Acquired leadership skills are born over the years of handling different situations. In the PSO's context of conflict mediation, they can be the best practice or lesson learned while experiencing managerial turmoil at the workplace. Innate when mediation is viewed on human nature, the ability to correspond with humanistic trend in management theory inspired by Maslow, [45] and McGregor [46]. Interestingly, the findings of the study relate the three binding elements of mediator's role before he attempts to mediate conflict. These three leadership attributes of credibility, astuteness and trustworthiness wrapped around mediator's capacity to mediate conflict rooted in the surface of his being. Gadamer ref.[43] enlightened that understanding of not so much on action of one's subjectivity but the placing of oneself within the process of truthfulness must lie on the mediator's image as a credible figure for conflict mediation. This would seem to justify the focus on impartiality in the mediation literature; an impartial mediator can be trusted by both sides because he has no interest in favoring or harming either side. For a mediator to be credible, he must have an incentive to tell the truth, Kydd, [47]. Mediator's credibility bridges understanding and agreement which parties are prepared for dialogue, and has inspired a great deal of theorizing about the idea of a ripe moment, Aggestam, [48]. Interestingly, being credible intertwines with being trustworthy. It is on this aspect that school administrators must maintain the trust and credibility which reduces perceptions of threat and legitimizes agreement that implicitly displayed by the third party during mediation process. It is considered as a useful instrument in bringing conflicting parties together, providing clearer communication, allowing the airing of grievances, reducing misperceptions and paving the way to a solution of basic differences based on agreement rather than violence; thus, ensuring the change of course of mediation fruitfully, Kelman, [49], Lax, and Sebenius, [50], Fisher, R. and Ury, [51], Kriesberg, [52].

Hence, it is safe to note that the goal for mediation is resolving conflict diplomatically. Diplomacy comes close to hermeneutics, by emphasizing that the parties in conflict should actively reflect their goals, actions and values while engaging in conflict resolution processes Rothman, [53]. Involvement of the third party in conflict requires astuteness or wise leadership driven by wisdom not on human intelligence which identifies limits of human information processing that cannot be predicted through technical applications Baltes and Staudinger, [54], Malan, and Kriger, [55] At an organizational level, this manifests as the ability "to detect the changing patterns in organizations overtime, rates of change occurring in internal and external environments of the organization" [55]. In other words, wise people recognize the value of excellent judgment. At an interpersonal level, this capability refers to wise people's ability to grasp and reconcile the paradoxes, changes, and contradictions of human nature. Undoubtedly the mediator's role should reflect action evaluation that encourages disputants to function as 'reflective practitioners' together with him by reflecting and examining the interacting goals, values and activities [49]. These reflections should be done systematically and continuously during the mediation process. Deepening mediator's role Sheppard, [56], Lewicki, and Sheppard, [57] have significantly formulated three possible reflective ways of handling mediation control: process control (how disputants interact during dispute resolution), content control (the substantive resolution of the dispute itself), motivational control (the source of power the third party uses to influence the disputants, e.g. persuasion, legitimate authority, threats and promises).

By and large, leaders are expected to wear various facets of leadership styles and attributes for him to stand still at his peak state of leadership influence. Relating self-monitoring ability and reflecting choice of conflict resolution strategy can be made possible encompassing the value of trust and credibility that deeply engrained in the inner self of an individual. Individuals considered to be highly self-monitored are more likely to adapt according to the situation and, as such, meet their own needs as well as those of others in an attempt at maintaining a good image as conflict mediator. Unless an individual communes with his inner self and discovers his qualities of credibility, astuteness and trustworthiness, he finds incapacitated to balance conflicts when mediating.

\section{Blending Role}

The fascinating revelations of school administrators in handling conflict mediation speak of the unilateral agreement that binds together between and among school stake holders where they are obliged to take part of. When being with the group, school administrators, being empowered to manage the school, have the moral obligation to go back to the members of the organization for feedback mechanism as their social responsibility. Putnam [58], for his part, expounded that social responsibility features organizational connections such as networks, norms, and social trust that facilitate coordination and cooperation for mutual benefit. This line vividly relates to the situation in the Philippine Schools overseas where school leaders have the responsibility to inform and consult the group whenever decision is made. Such consultation reflects the undefiled image of school leaders emulated by their subordinates. Collaborative behavior is strongly desirable as a way of managing and 
resolving conflict notwithstanding individual differences, the value of a collaborative style and the desirability of achieving integrative agreements which were simply taken for granted by some writers but widely acclaimed by others ref [51], Follett, [59], Pneuman, and Bruehl, [60]. Justifications offered Blake, and Mouton, [61] highlighted the value of consultative and integrative role of mediators that may lead to reduction in antagonism, to healing cleavages, to restoration of real and imagined injustices, to ameliorate alienation and minimization of conformity. Pruitt, [62] pointed out that integrative agreements are likely to be more stable, to strengthen the parties' relationship, and to contribute to broader community welfare. The give-and-take or face-to-face internal group interaction, coupled with the organizational imperative for cooperative endeavors, encourages the development of norms such as reciprocity and trust. Compromise is usually called for and willingness to respect the views and affiliations of others becomes a social necessity within the group Brehm, and Rahn. [63]. Enlightened by this notion, process consultation according to Walton [64] develops ideal resolution of interpersonal and intergroup disputes based on human relations and humanistic discussions. This intervention combines elements of mediation with the third party's engineering of a direct confrontation between the parties is designed to facilitate the problem-solving behavior [64].

Comparatively, deliberated interaction of two or more social complex redefines the terms of organizational interdependence that applies to individuals as well as 'social units' such as groups and organizations Walton, and Mc. Kersie, [65]. This consultative process of mediation remains functional particularly if the mediator's purpose is to save the image of the group and the organization as well. It is very impressive that mediator's responsibility toward the stakeholder is always at its prime importance and must occupy largely the broad capacity of school leaders to play their role not just managers but the saving vessel of the organizations. In human organizations, leaders and managers are always at the forefront as vanguards of the preserved corporate philosophy and values [63] without complacency and inhibitions. Leaders, in the advent of conflict and resistance, must always display a redemptive or restorative attitude to mend shattered relationship. Such operative metaphors of the redemptive culture were related to social and collective projects that embodied universal and social solutions on conflict resolution that describe deficiencies in social reality Ref. [2]. This redemptive theme helped focus on social issues leading to disagreements but mediators must keep the key of order and should maintain the flow of discussion ensuring that at the end of the mediation process restoration of relationship and the redeeming compass of organization remain its course as bearer of truth and implementer of organizational change.

As findings revealed, magnifying emulative image is undeniably important for administrators in conflict mediation. It is an intentional interpretation of behavioral reenactment that includes local or stimulus enhancement, action draws an observer's attention to particular environmental locations, stimulus consequences of the demonstration and mimicking Heyes, [66], Tomasello, [67],Want and Harris, [68]. It is imperative to say that school leaders and managers across disciplines must develop a character worth emulating for their subordinates to keep and adore. Since emulation is a social learning processes that develops configurative response from the given stimulus Huang, and Charman, [69], leaders are like parents who are looked up to by their children with high regard and with the tendency to be the subject for imitation. It is in this attribute that the image of a being a leader is crucial in conflict mediation. Translated in managerial terms, it is clear that intentional imitation, emulation and mimicry play a role in determining specific response ref [69] to what a leader displays, shows, and projects. In the old adage that says what the adults do the child follows is simply a clear indication of how emulative the image of a leader is. Thus in the negotiation table, mediator shall carefully display a joint process of decision making, where disputants and the stakeholders are at par with the semblance of forging an agreement that they can bring together into a single outcome not just a form of mediation concession but a human expression for emulation Zartman, [70]. Human expressions contain a meaningful component, which have to be recognized as such by a subject and transposed into his or her own system of values and meanings.

The blending role that binds with consultative, redemptive and emulative, as leadership attributes exemplifies the potent capability of a leader to exercise his authority cautiously and productively. Said attributes cannot be underestimated in the context of conflict mediation for they hold through the leadership image of a leader worthy of respect and emulation not only by his people but also by the school stakeholders.

\section{CONCLUSION}

Capitalizing the power of phenomenological design as a means to understand multiple layers of human experiences, this study has meaningfully identified the distinct role of a select group of school administrators whose mediation moves and decisions determine the extent to which school problems and issues are substantially and humanely addressed. Interestingly, the triad of bracketing, balancing and blending roles clearly defines the regulative dynamics and the challenges which are vital means in giving the disputants the true confidence as they submit themselves to mediation process under the control of their leader. The balancing role invites a school leader to subject himself to self-evaluation geared toward exemplifying credibility, astuteness, and trustworthiness prior to engaging in the negotiation process. Cognizant to the need for social responsibility in school leaderships, the blending role of a mediator deepens a leader's ability to be consultative, redemptive and emulative. Said attributes liberate the mediator to powerfully exercise his leadership influence in conflict mediation. In this study the emerged trilogy of mediation roles is defined as the school leaders' control filters that enable the organization to breathe freely and work efficiently despite the challenges of disagreements, conflicting situations and heated passion. Presumably, said trilogy of mediation roles of school administrators provides the life-giving where courage and confidence render the 
school's relational atmosphere less stressful yet more humane and productive.

There is no doubt that human organizations have different conflict occurrences. The emerged trilogy of mediation roles in this study is indeed a powerful lens in underscoring how intersections of human perspectives, thinking, and behavior can be understood in both positivist and naturalist means. The collective description of each of the mediator's role invites researchers and management experts to validate an instrument or metric system that will identify specific indicators and items of the three mediating roles. Said instruments can be tested in a more aggregate and cross sectional section. Results can expectedly generate valuable insights in structuring mediation training programs centered on the trilogy of mediation roles.

\section{REFERENCES}

[1] J. Wall, J. Stark, and R. Standifer, "Mediation: A current review and theory development," Journal of Conflict Resolution, vol. 45, no. 3, pp. 370-391, 2001.

[2] P. Wagner, C. Weiss, B. Wittrock, and H. Wollman, Social Sciences and Modern States: National Experiences and Theoretical Crossroads New York: Cam-bridge University Press. 1991

[3] M. Kleiboer and P. Hart, "Time to talk: Multiple perspectives on timing of international mediation," Cooperation and Conflict, vol. 30, no. 4 pp. 307-348, 1995.

[4] J. Vasquez, J. Turner, J. Sanford, and L. Stamato, Beyond Confrontation: Learning Conflict Resolution in the Post-Cold War Era Ann Arbor: University of Michigan Press, 1995.

[5] A. Whiten and R. Ham, "On the nature of imitation in the animal kingdom: reappraisal of a century research," Advances in the Study of Behaviour, London: Oxford University Press, vol. 21, no. 2, pp 239-283, 1992.

[6] C. Mitchell and K. Webb, New Approaches to International Mediation, New York: Greenwood Press, 1988.

[7] K. Kressel and D. Pruitt, Mediation Research: the Process and Effectiveness of Third-Party Intervention, San Francisco: Jossey Bass Publishers, 1989

[8] J. Rubin, D. Pruitt, and S. Kim, Social Conflict: Escalation, Stalemate, and Settlement, 2nd ed., New York: McGraw-Hill, 1994. "Resolving international conflicts: the theory and practice of mediation," in Cultural Aspects of Mediation, R. Cohen ed., Boulder, CO: Lynne Rienner, 1996.

[9] R. Patai, The Arab Mind, New York: Scribners, 1977.

[10] R. Singh and J. Singh, The Darker Side of Worker-Management Relationships in a Coal Area in India in Norm Violations and Intergroup Relations, London: Oxford University Press, 1992.

[11] R. Callister and A. Wall, "Japanese Community and Organization Mediation," Journal of Conflict Resolution, vol. 41, no. 7, pp. 311-28, 1997.

[12] J. Wall and M. Blum, "Community mediation in the People's Republic of China," Journal of Conflict Resolution, vol. 35, no. 1, pp. 3-20, 1991.

[13] L. Jocano, Anthropology of the Filipino People, Punlad Research House Inc., 1998.

[14] R. Callister and J. Wall, "Thai and U.S. community mediation author," The Journal of Conflict Resolution, vol. 48, no. 4, pp. 573-598, 2004.

[15] P. Regan, "Conditions of successful third-party intervention in intrastate conflicts," Journal of Conflict Resolution, vol. 40, no. 6, pp. 336-359, 1996

[16] N. Vidmar, "An assessment of mediation in a small claims court," Journal of Social Issues, vol. 41, no. 2, pp. 127-144, 1985.

[17] J. Brett and S. Goldberg, "Grievance mediation in the coal industry: a field experiment," Industrial and Labor Relations Review, vol. 37, no. 3, pp. 3-17, 1983.

[18] J. Folberg and A. Taylor, Mediation: A Comprehensive Guide to Resolving Conflicts Without Litigation, Jossey Bass, San Francisco, U.S.A, 1984

[19] Berger and T. Luckman, The Social Constructivism of Reality, Penguin University Books, 1976.

[20] J. Burton, Violence Explained, Manchester: Manchester University Press. 1997.
[21] J. Bercovitch, Studies in International Mediation, London: Palgrave Princeton University Press., 2003.

[22] T. Princen, Intermediaries in Inter-national Conflicts, Princeton, NJ: Princeton University Press, 1992.

[23] T. Popkewitz, U.S. Teacher Education Reforms: Regulatory Practices of the State, University, and Research, Albany: State University of New York Press, 1993.

[24] S. Touval and W. Zartman, International Mediation in Theory and in Practice, Boulder, Co. 1985.

[25] C. McWilliam, A. Kothari, C. W. Griffin, D. Forbes, and B. Leipert "Evolving the theory and praxis of knowledge translation through social interaction: a social phenomenological study," Implementation Science, vol. 4, no. 2, pp. 1-14, 2009.

[26] G. Keltchtermans and K. Ballet, "The micropolitics of teacher induction a narrative bibliographical study on teacher socialization," Teaching and Teacher Education, vol. 18, no. 1, pp. 05-120, 2002.

[27] P. Atkinson and A. Coffey, "Revisiting the relationship between participant observation and interviewing," in Handbook of Interview Research Thousand Oaks, J. F. Gubrium and J. A. Holstein eds., CA, Sage, 2002.

[28] R. Dingwall, "Accounts, interviews and observations," in Context and Method in Qualitative Research, G. Miller and R. Dingwall eds., London, Sage, 1997.

[29] D. Silverman, "Towards an aesthetics of research," in Qualitative Research: Theory, Method and Practice London, D. Silverman ed., Sage, 1997

[30] R. Bogdan and S. Biklen, Qualitative Research for Education: An Introduction to Theory and Methods, Boston: Allyn and Bacon, Inc. 1982.

[31] J. Welman and S. J. Kruger, Research Methodology for the Business and Administrative Sciences, Johannesburg, South Africa: International Thompson, 1999.

[32] G. Faulkner and A. Sparkes, "Exercise as therapy for schizophrenia," Journal of Sports and Exercise Psychology, vol. 21, no. 1, pp. 52-69, 1999.

[33] R. Lewicki and B. Sheppard, "Choosing how to intervene: factors affecting the use of process and outcome control in third party dispute resolution," Journal of Occupational Behavior, vol. 6, no. 5, pp. 49-64, 1985.

[34] O. Young, The Intermediaries: Third Parties in International Crises, Princeton: Princeton University Press, 1967.

[35] S. Touval, "Biased intermediaries: Theoretical and historical considerations," Jerusalem Journal of International Relations, vol. 1 , no. 1, pp. 51-69, 1975.

[36] S. Touval, The Peace Brokers: Mediators in the Arab-Israeli Conflict, Princeton: Princeton University Press. 1982.

[37] L. Terris and Z. Maos, "Rational mediation: a theory and a test," Journal of Peace Research, vol. 42, no. 5, pp. 563-583, 2005.

[38] J. Stein, Image, Identity and Conflict Resolution, in Crocker and Hampson, London: Oxford University Press, 1996.

[39] C. Bassiouni, "Searching for peace and achieving justice: the need for accountability," Law and Contemporary Problems, vol. 59, no. 4, pp. 9-28, 1996.

[40] W. Felstiner and L. Williams, "Mediation as an alternative to criminal prosecution: Ideology and limitations," Law and Human Behavior, vol. 2, no. 3, pp. 349-365, 1978.

[41] S. Darwall, "Philosophy and phenomenological research," International Phenomenological Society, vol. 49, no. 3, pp. 507-515, 1989.

[42] H. Gadamer, Truth and Method, London: Sheed and Ward. 1979.

[43] J. Hocker and W. Wilmot, Interpersonal Conflict, 2nd ed, Wm. C. Brown, New York. 1985

[44] A. Maslow, Motivation and Personality, Harper and Row, New York. Press, 1954

[45] D. McGregor, The Human Side of Enterprise, McGraw Hill, New York. Press, 1960.

[46] A. Kydd, "Which side are you on? Bias, credibility, and mediation," American Journal of Political Science, vol. 47, no. 4, pp. 597-611, 2003.

[47] K. Aggestam, Reframing and Resolving Conflict, Lund: Lund University Press, 1999.

[48] H. Kelman, Mediation in International National Relations: Multiple Approaches to Conflict Management, Basingstoke and London: Macmillan, 1987.

[49] D. Lax and J. Sebenius, The Manager as Negotiator, Free Press, New York, 1986

[50] R. Fisher and W. R. Ury, Getting to Yes, Houghton-Mifflin, Boston. U.S.A, 1981. 
[51] L. Kriesberg, The Sociology of Social Conflict, Prentice Hall, Englewood Cliffs, NJ. 1973.

[52] J. Rothman, "Action evaluation and conflict resolution: in theory and practice," Mediation Quarterly, vol. 15, no. 2, pp. 119-131, 1997.

[53] P. B. Baltes and U. M. Staudinger, "A metaheuristic (pragmatic) to orchestrate mind and virtue toward excellence," Journal of American Psychologist, vol. 55, no. 2, pp. 122-136, 2000.

[54] L. Malan and M. Kriger, "Making sense of managerial wisdom," Journal of Management Inquiry, vol. 7, no. 8, pp. 242-251, 1998.

[55] B. Sheppard, "Managers as inquisitors: Some lessons from the law," in Negotiating in Organizations, M. A. Bazerman and R. J. Lewicki eds., Sage Publications, Beverly Hills, 1983.

[56] R. Lewicki and B. Sheppard, "Choosing how to intervene: Factors affecting the use of process and outcome control in third party dispute resolution," Journal of Occupational Behavior, vol. 6, no. 5, pp. 49-64, 1985.

[57] R. Putnam, Making Democracy Work: Civic Traditions in Modern Italy, Princeton, NJ. Princeton University Press, 1993.

[58] M. Follett, "Constructive conflict," in Dynamic Administration: The Collected Papers of Mary Parker Follett, H. C. Metcalf and L. Urwick eds., Harper, New York, 1940.

[59] R. Pneuman and M. Bruehl, Managing Conflict, Prentice-Hall, Englewood Cliffs, 1982.

[60] R. Blake and J. Mouton, The New Managerial Grid, Gulf, Houston, Texas, 1978

[61] D. G. Pruitt, "Achieving integrative agreements," in Negotiating in Organizations, M. A. Bazerman and R. J. Lewicki eds., Sage Publications, Beverly Hills, 1983.

[62] J. Brehm and W. Rahn, "Individual-level evidence for the causes and consequences of social capital," American Journal of Political Science, vol. 41, no. 3, pp. 999-1023, 1997.

[63] R. Walton, Interpersonal Peacemaking, Addison Wesley, Reading, MA, 1969.

[64] R. Walton and R. Mc. Kersie, A Behavioral Theory of Labor Negotiations, Sage, Publications, Beverly Hills, 1965.

[65] C. Heyes, "Theory of mind in nonhuman primates," Behavioural and Brain Sciences, vol. 21, no. 8, pp. 101-114, 1998.
[66] M. Tomasello, "Cultural transmission in the tool use and communicatory signaling of chimpanzees," in "Language" and Intelligence in Monkeys and Apes: Comparative Developmental Perspectives, S. T. Parker and K. R. Gibson eds., Cambridge: Cambridge University Press, 1990.

[67] S. Want and P. L. Harris, "How do children ape? Applying concepts from the study of non-human primates to the developmental study of 'imitation' in children," Journal of Developmental Science, vol.5, no. 2, pp. 1-13, 2002.

[68] C. T. Huang and T. Charman, "Gradations of emulation learning in infants' imitation of actions on objects," Journal of Experimental Child Psychology, 2005.

[69] W. Zartman, Negotiating Identity: From Metaphor to Process, International Negotiation, vol. 6, no. 2, pp. 137-140, 2001.

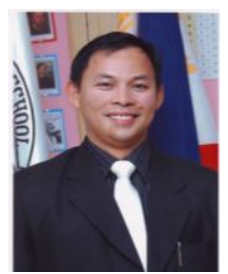

Alexander S. Acosta was born on July 15, 1970 in Cebu, Philippines. He graduated with the degree of bachelor in elementary education, major in English at the University of the Visayas, Cebu, Philippines in 1990. He finished his master's degree program majoring in teaching English as a second language (TESL) at Cebu Normal University, Cebu, Philippines in 2000. A doctor of philosophy major in educational management graduate in 2010 at the University of Santo Tomas, Manila, Philippines and got the highest award of his dissertation as Summa Cum Laude. He is currently working as the school principal of the Philippine School Doha, State of Qatar for thirteen (13) years. He has been a resource speaker in the field of leadership and of education. He is keen to conducting research studies in both corporate and educational leadership and pedagogical approaches in education. Has published and co-authored researches that were accepted for paper presentation in International conferences and fora. 